\title{
IMPLEMENTASI AUGMENTED REALITY PEMASARAN RUMAH PT. RIKA BERSAUDARA SAKTI MENGGUNAKAN METODE MARKER BASED TRACKING PADA BROSUR PERUMAHAN
}

\author{
Ekawati Yulsilviana $^{1)}$, Basrie $^{2)}$, Ary Wida Saputra ${ }^{3)}$ \\ 1,2,3 Teknik Informatika, STMIK Widya Cipta Dharma \\ ${ }_{1,2,3}$ Jl. M. Yamin No.25, Samarinda, 75123 \\ E-mail : ekawati_stmik@yahoo.com ${ }^{1)}$, basriecarnate@gmail.com ${ }^{2)}$, arywidas@gmail.com ${ }^{3)}$
}

\begin{abstract}
ABSTRAK
Kebutuhan informasi dalam media promosi masih banyak menggunakan cara konvensional dan belum memadukan unsurunsur teknologi modern. Augmented Reality (AR) adalah bidang penelitian komputer yang menggabungkan data grafis 3 dimensi dengan dunia nyata atau dengan kata lain realita yang ditambahkan ke suatu media. Media pemasaran yang digunakan oleh PT. Rika Bersaudara Sakti saat ini menggunakan media brosur yang berisi gambar 2 dimensi dan informasi tentang rumah yang dipasarkan sehingga banyak para pembeli yang kurang tertarik karena pembeli tidak bisa melihat bentuk rumah secara lagsung, namun akan sangat menarik jika gambar pada brosur disajikan dengan berbentuk 3 dimensi.
\end{abstract}

Implementasi augmented reality pemasaran rumah PT.Rika Bersaudara Sakti menggunakan metode marker based tracking pada brosur perumahan ini diawali dengan penginstalan software pendukung augmented reality yaitu ARToolKit. Merancang desain 3D objek rumah yang dipasarkan PT,Rika Bersaudara Sakti menggunakan Google SketchUp, merancang desain marker dan desain brosur perumahan PT. Rika Bersaudara Sakti menggunakan Adobe Photoshop CS4.

Berdasarkan hasil pengujian beta, Implementasi augmented reality pemasaran rumah PT.Rika Bersaudara Sakti menggunakan metode marker based tracking pada brosur perumahan ini dapat menjadi salah satu media alternatif untuk promosi kepada calon pembeli dan menarik sebagai media promosi yang memperlihatkan rumah-rumah yang dipasarkan PT. Rika Bersaudara Saktidengan cara yang lebih interaktif

Kata Kunci: Augmented Reality, Pemasaran Rumah, Brosur, Marker Based Tracking

1. PENDAHULUAN

Brosur adalah promosi barang atau jasa perusahaan dengan menjualkan sebuah perusahaan yang bergerak sebagai promosi pemasaran untuk melihat brosur yang diperlihatkan dengan serius agar masyarakat bisa menjaga nama baik brosur supaya dalam memperhitungkan media yang percetakannya harus menjaga hubungan baik dengan promosi barang atau jasa yang sudah bahan baku. Media brosur yang dipakai saat ini hanya menampilkan rumah dalam bentuk foto untuk memberikan gambaran kepada para calon pembeli, sehingga mereka tidak dapat melihat bentuk rumah yang ditawarkan dari berbagai sudut. Lokasi kantor pemasaran yang jaraknya tidak berdekatan dengan lokasi perumahan juga merupakan salah satu faktor yang membuat para calon pembeli tidak dapat melihat langsung bentuk nyata dari rumah-rumah yang ditawarkan. Agar para konsumen dapat lebih memvisualisasikan objek perumahan yang akan dipilih maka diperlukan sebuah teknologi yang dapat mendukung hal tersebut, salah satunya yaitu dengan menggunakan teknologi augmented reality. Teknologi augmented reality yang mulai banyak digunakan pada saat ini, dapat menapilkan benda maya baik dalam bentuk 2D maupun 3D ke dalam lingkungan nyata yang dapat ditampilkan secara real time.
Augmented Reality (AR) adalah bidang penelitian komputer yang menggabungkan data grafis 3D dengan dunia nyata atau dengan kata lain realita yang ditambahkan ke suatu media. Media ini dapat berupa kertas, sebuah marker atau penanda melalui perangkatperangkat input tertentu.

Marker Augmented Reality merupakan tipe Augmented Reality yang mengenali marker dan mengidentifikasi pola dari marker tersebut untuk menambahkan suatu objek virtual ke lingkungan nyata.

Penerapan teknologi augmented reality dapat dijadikan solusi untuk mengatasi permasalahan tersebut. Dengan membangun sebuah aplikasi brosur menggunakan augmented reality, diharapkan kedepanya aplikasi ini dapat lebih memberikan informasi kepada para calon pembeli, dan para calon pembeli juga dapat lebih memvisualisasikan perumahan yang dipasarkan, serta aplikasi ini juga diharapkan dapat berinteraksi dengan para pengguna secara langsung.

\section{RUANG LINGKUP PENELITIAN}

Permasalahan difokuskan pada :

1. Augment Reality (AR) ini hanya dapat dijalankan dengan menggunakan personal computer dan notebook yang telah memiliki fasilitas kamera digital internal ataupun eksternal. 
2. Metode yang digunakan adalah marker based tracking

3. Fasilitas yang akan diperkenalkan pada brosur ini hanya fasilitas bangunan perumahan tampak luar yang dipasarkan oleh PT. Rika Bersaudara Sakti

\section{BAHAN DAN METODE}

Adapun bahan dan metode yang gunakan dalam membangun game ini yaitu:

\subsection{Augmented Reality}

Menurut Ronald T.Azuma (1997) mendefinisikan Augmented reality sebagai penggabungan benda benda nyata dan maya di lingkungan nyata, berjalan secara interaktif dalam waktu nyata dan terdapat integrasi dan maya dimungkinkan dengan teknologi tampilan yang sesuai, interaktivitas dimungkinkan melalui perangkatperangkat input tertentu, dan integrasi yang baik memerlukan penjelasan yang efektif. Sedangkan menurut Stephen Coward dan Mark Faila dalam bukunya yang berjudul Augmented reality a partical guide, mendefinisikan bahwa Augmented reality merupakan cara alami untuk mengeksplorasi objek 3D dan data, AR merupakan suatu konsep perpaduan antara visual reality dengan world reality. Sehingga objek objek virtual 2 dimensi (2D) teknologi AR, pengguna dapat melihat dunia nyata yang ada di sekelilingnya dengan penambahan obyek virtual yang dihasilkan komputer. Dalam buku "Hand Book of Augmented reality", Augmented reality bertujuan menyederhanakan hidup pengguna dengan membawa informasi maya yang tidak hanya untuk lingkungan sekitar, tetapi juga untuk setiap melihat langsung lingkungan dunia nyata, seperti livestreaming video. AR meningkatkan pengguna presepsi dan interaksi dengan dunia nyata.

Menurut penjelasan Haller, Billinghurst dan Thomas (2007), riset Augment Reality bertujuan untuk mengembangkan teknologi yang memperbolehkan penggabungan secara realtime terhadap digital content yang dibuat oleh komputer dengan dunia nyata. Augmented reality meemperbolehkan pengguna melihat objek maya dua dimensi atau tiga dimensi yang diproyeksi terhadap dunia nyata. (Emerging Technologies of Augmented reality).

\subsection{Marker}

Marker merupakan sebuah gambar berpola khusus yang sudah dikenali oleh Template Memory ARToolkit. Dimana marker tersebut berfungsi untuk dibaca dan dikenali oleh kamera lalu dicocokkan dengan template ARToolkit. Setelah itu, baru kamera akan melakukan render objek 3D diatas marker.

Pada umumnya Marker yang bisa dikenali ARToolkit hanya marker dengan pola berbentuk kotak dengan bingkai hitam didalamnya. Akan tetapi seiring berkembangnya zaman banyak pengembang Augmented reality yang dapat membuat marker tanpa bingkai hitam.

\subsection{Marker Augmented Reality}

Menurut Chari (2008) Marker Augmented reality merupakan tipe Augmented reality yang mengenali marker dan mengidentifikasi pola dari marker tersebut untuk menambahkan suatu objek virtual ke lingkungan nyata. Marker merupakan ilustrasi persegi hitam dan putih dengan sisi hitam tebal, pola hitam ditengah persegi dan latar belakang putih. Contoh marker dapat dilihat pada gambar 1 .

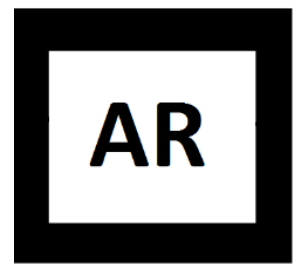

Gambar 1. Contoh Marker

Titik koordinat virtual pada marker berfungsi untuk menentukan posisi dari objek virtual yang akan ditambahkan pada lingkungan nyata. Posisi dari objek virtual akan terletak tegak lurus dengan marker. Objek virtual akan berdiri segaris dengan sumbu $Z$ serta tegak lurus terhadap sumbu X (kanan atau kiri) dan sumbu Y (depan atau belakang) dari koordinat virtual marker. Ilustrasi dari titik koordinat virtual marker dapat dilihat pada gambar 2 .

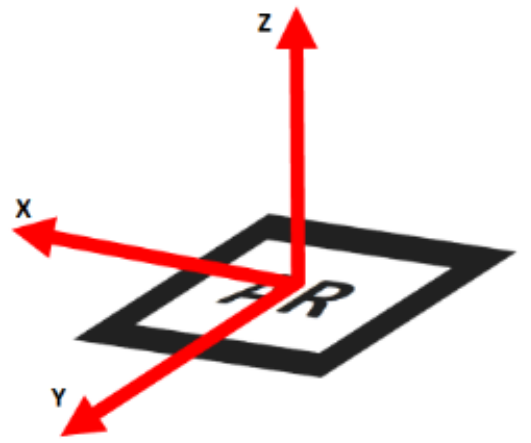

Gambar 2. Titik Koordinat Virtual pada Marker

\subsection{ArtoolKit}

Pengertian ARToolkit secara luas adalah software library untuk membangun Augmented reality dan aplikasi ini adalah aplikasi yang melibatkan overlay pencitraan virtual ke dunia nyata Untuk melakukan hal tersebut, ARToolkit menggunakan cara dengan pelacakan video, agar dapat menghitung posisi kamera yang nyata dengan mengorientasikan pola pada kertas marker secara realtime. Dari semua software library, ARToolkit adalah salah satu software library yang paling klasik dan yang pertama kali dibuat didunia oleh seorang ilmuan Jepang bernama Hirokazu Kato.

ARToolkit memberikan kemudahan dalam penggunaan bagi user yang sedang belajar Augmented reality jika dibandingkan dengan software library lainnya. Selain dari segi kemudahan dalam penggunaannya, ternyata software library ARToolkit juga bersifat open source sehingga siapapun dapat memodifikasi ARToolkit tanpa harus membayar lisensi sepeserpun.

\subsection{Blender}

Blender adalah salah satu software open source yang digunakan untuk membuat konten multimedia khusunya 3Dimensi. Blender memiliki berbagai fungsi antara lain :

a. Blender adalah aplikasi pemodelan tiga dimensi yang dapat membuat sebuah karakter untuk film.

b. Blender memiliki sebuah alat yang kuat untuk pewarnaan permukaan model. 
c. Blender memiliki sebuah fasilitas dalam rigging dan animasi yang sangat kuat. Model tiga dimensi yang dibuat dapat dirancang untuk bergerak dan beraksi sedemikian rupa.

d. Blender memiliki mesin rendering sendiri dan dapat dianggap layaknya studio pencahayaan yang lengkap untuk sebuah film.

e. Tidak seperti paket aplikasi 3D lainnya, Blender memiliki compositing module sendiri, sehingga hasil live shoot bisa langsung di masukkan dan diintegrasikan dengan model tiga dimensi. Blender juga memiliki editor pengurutan video yang unik, sehingga memungkinkan untuk memotong dan mengedit video tanpa harus bergantung pada aplikasi pihak ketiga tambahan untuk tahap editing akhir produksi.

f. Selain semua itu, Blender juga memiliki fasilitas Game Engine.

\subsection{Tahapan Pengembangan Multimedia}

Menurut Binanto (2010), metodologi pengembangan multimedia terdiri dari enam tahap, yaitu concept (pengonsepan), design (pendesainan), meterial collecting (pengumpulan materi), assembly (pembuatan), testing (pengujian), dan distribution (pendistribusian). Keenam tahap ini tidak dapat bertukar posisi. Meskipun begitu, tahap concept memang harus menjadi hal yang pertama kali dikerjakan.

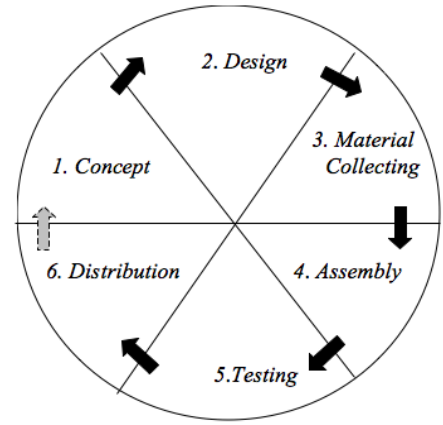

Gambar 3. Tahapan Pengembangan Multimedia

Tahapan Pengembangan Multimedia Meliputi :

1. Concept

Tahapan concept (pengonsepan) adalah tahap untuk menentukan tujuan dan siapa pengguna program (indentifikasi audiens). Tujuan dan penguna akhir program berpengaruh pada nuansa multimedia sebagai pencerminan dari indentitas organisasi yang menginginkan informasi sampai pada pengguna akhir.Karakteristik pengguna termasuk kemampuan pengguna juga perlu dipertimbangkan karena dapat memengaruhi pembuatan desain.

Selain itu, tahap ini juga akan menentukan jenis aplikasi (presentasi, interaktif, dan lain-lain) dan tujuan aplikasi (hiburan, pelatihan, pembelajaran dan lain-lain). Dasar aturan untuk perancangan juga ditentukan pada tahap ini, misalnya ukuran aplikasi, target, dan lain-lain. Output dari tahap ini biasanya berupa dokumen yang bersifat naratif untuk mengungkapkan tujuan projek yang ingin dicapai.

\section{Design}

Design (perancangan) adalah tahap pembuatan spesifikasi mengenai arsitektur program, gaya, tampilan, dan kebutuhan material/bahan untuk program. Spesifikasi dibuat serinci mungkin sehingga pada tahap berikutnya, yaitu material collecting dan assembly, pengambil keputusan baru tidak diperlukan lagi, cukup menggunakan keputusan yang sudah ditentukan pada tahap ini. Meskipun demikian, pada prakteknya, pekerjaan proyek pada tahap awal masih akan sering mengalami penambahan bahan atau pengurangan bagian aplikasi, atau perubahan-perubahan lain.

3. Material Collecting

Material Collecting adalah tahap pengumpulan bahan yang sesaui dengan kebutuhan yang dikerjakan. Bahan-bahan tersebut, antara lain gambar clip art, foto, animasi, video, audio, dan lain-lain yang dapat diperoleh secara geratis atau dengan pemesanan kepada pihak lain sesuai dengan rancangannya.Tahap ini dapat dikerjakan secara paralel dengan tahap assembly. Namun, pada beberapa kasus, tahap material collecting dan tahap assembly akan dikerjakan secara linear dan tidak paralel.

4. Assembly

Tahap Assembly adalah tahap pembuatan semua objek atau bahan multimedia. Pembuatan aplikasi didasarkan pada tahap design, bagan alir, dan /atau struktur navigasi.

5. Testing

Tahap Testing (pengujian) dilakukan setelah menyelesaikan tahap pembuatan (assembly) dengan menjalankan aplikasi/program dan melihatnya apakah ada kesalahan atau tidak. Tahap pertama pada tahap ini disebut tahap pengujian alpha (alpha test) yang pengujiannya dilakukan oleh pembuat atau lingkungan pembuatnya sendiri. Setelah lolos dari pengujian alpha, pengujian beta yang melibatkan penggunaan akhir akan di lakukan.

\section{Distribution}

Pada tahap ini, aplikasi akan disimpan dalam suatu media penyimpanan. Jika media penyimpanan tidak cukup untuk menampung aplikasinya, komprensi terhadap aplikasi tersebut akan dilakukan. Tahap ini juga dapat disebut tahap evaluasi untuk pengembangan produk yang sudah jadi supaya menjadi lebih baik. Hasil evaluasi ini dapat digunakan sebagai masukkan untuk tahap concept pada produk selajutnya.

\section{RANCANGAN APLIKASI}

Perancangan aplikasi Implementasi Augmented Reality Pemasaran Rumah PT. Rika Bersaudara Sakti ini menggunakan alat bantu flowchart sebagai salah satu cara untuk mempermudah dalam pembuatan aplikasi ini.

Alur flowchart dimulai dengan tampilan menu utama "Mulai" dan Tombol Keluar. Saat memilih menu "Mulai" maka Property sheet Properties dari Webcam akan muncul dan pengguna akan mengatur resolusi dari tampilan webcam tersebut. Setelah resolusi telah dipilih maka webcam akan muncul. Lalu pengguna akan 
menunjukkan marker yang ada pada brosur perumahan berbasis Augmented Reality ke webcam, lalu aplikasi akan melakukan identifikasi marker dan melakukan rendering objek sesuai dengan marker yang ditunjukkan oleh pengguna. Objek rumah 3 Dimensipun akan tampil diatas marker. Untuk menampilkan objek lain pengguna hanya menunjukkan jenis marker lain yang terdapat pada buku. Jika sudah maka pengguna bisa keluar program dengan menekan tombol keluar. Seperti yang terlihat pada gambar 4 .

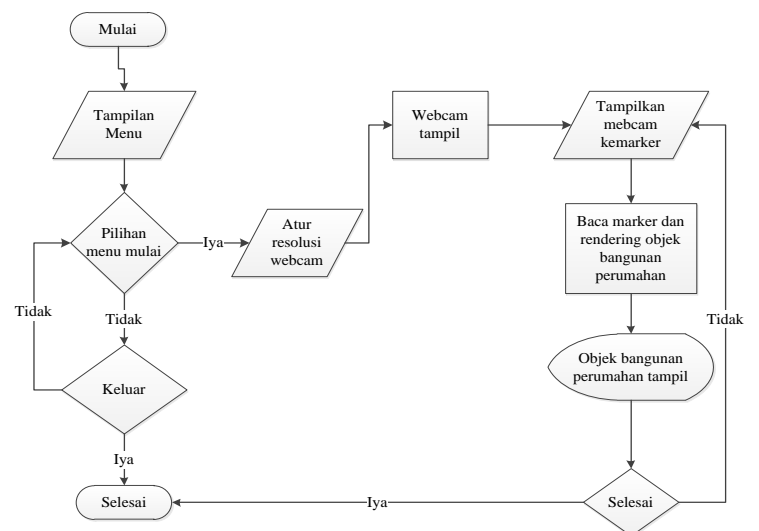

Gambar 4. Flowchart Program

\section{IMPLEMENTASI}

Hasil implementasi berdasarkan analisis dan perancangan adalah sebagai berikut :

1. Marker dalam Pembelajaran bangun ruang berbasis Augmented Reality

Tabel 1. Tabel Marker

\begin{tabular}{|c|c|l|}
\hline No & \multicolumn{1}{|c|}{ Marker } & \multicolumn{1}{|c|}{$\begin{array}{l}\text { Marker type } 36 \\
\text { merupakan Marker untuk } \\
\text { menampilkan objek } \\
\text { rumah 3 dimensi type 36. }\end{array}$} \\
\hline 2 & type 45 \\
\hline 3 & & $\begin{array}{l}\text { Marker } \\
\text { merupakan Marker untuk } \\
\text { menampilkan objek } \\
\text { rumah 3 dimensi type 45. }\end{array}$ \\
\hline
\end{tabular}

2. Tampilan Мепи Utama

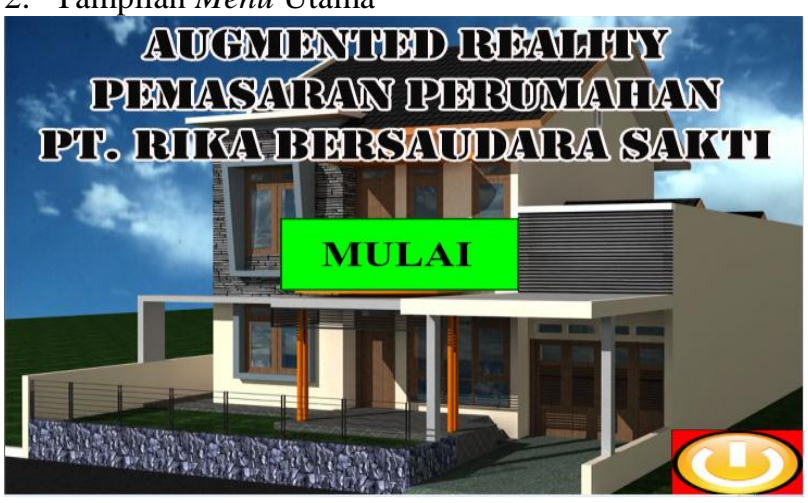

Gambar 5. Menu Utama

Menu utama memiliki 2 tombol yaitu tombol mulai dan tombol keluar. Tombol mulai berfungsi untuk masuk ke webcam dengan aplikasi Augmented Reality. Sedangkan tombol keluar berfungsi untuk keluar dari program.

3. Tampilan objek 3 dimensi bangunan perumahan PT. Rika Bersaudara Sakti berbasis Augmented Reality

Objek 3 dimensi bangunan perumahan PT. Rika Bersaudara Sakti menampilkan keseluruhan bangunan serta luas tanah dan bangunan dari type-type perumahan yang dipasarkan oleh PT. Rika Bersaudara Sakti sesuai dengan observasi lapangan.

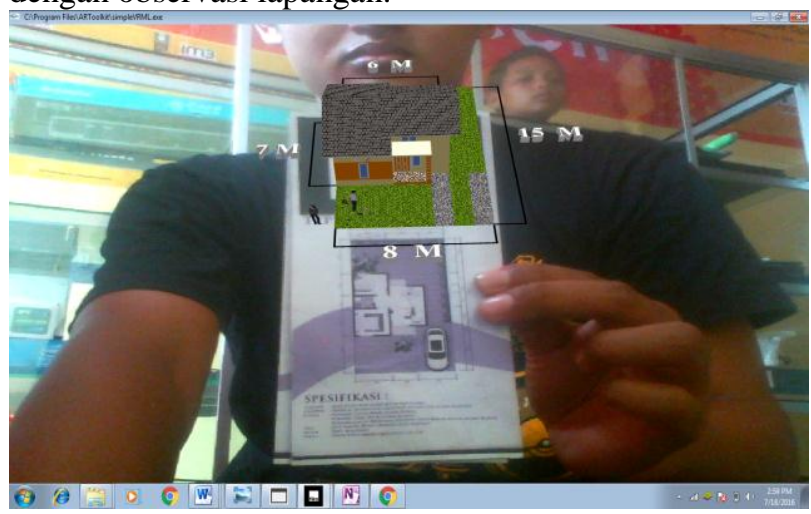

Gambar 6. Tampilan objek 3 dimensi Type 45 bangunan perumahan PT. Rika Bersaudara Sakti berbasis Augmented Reality

4. Tampilan brosur perumahan PT. Rika Bersaudara Sakti berbasis augmented reality

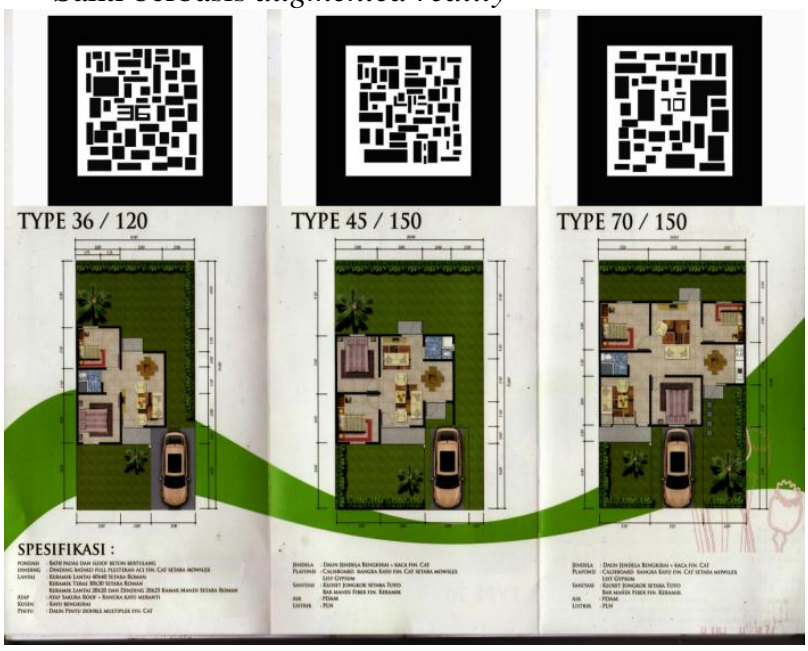

Gambar 7. Tampilan Brosur 
Seperti yang terlihat pada gambar 7, Brosur berisi informasi type-type perumahan yang dipasarkan, luas tanah dan bangunan, serta sepesifikasi bahan-bahan yang digunakan dalam pembuatan bangunan tersebut.

5. Keterbatasan aplikasi Implementasi Augmented Reality Pemasaran Rumah PT. Rika Bersaudara Sakti Aplikasi Implementasi Augmented Reality Pemasaran Rumah PT. Rika Bersaudara Sakti memiliki beberapa keterbatasan dalam hal pemakaiannya yang dipengaruhi oleh beberapa faktor.

1). Oklusi

Objek virtual hanya akan muncul ketika marker ditangkap kamera. Hal ini membatasi ukuran atau gerakan dari objek virtual. Ini juga berarti bahwa jika pengguna menutupi pola yang ada pada marker dengan tangan mereka atau benda lain, objek virtual akan menghilang.

2). Marker

Objek virtual akan muncul jika marker berhasil dikenali oleh ARToolkit. Marker yang dapat dikenali adalah marker dengan pola tertentu yang telah dikenalkan/diinputkan pada ARToolkit. Dilakukan pengujian untuk mengetahui apakah marker dapat dikenali jika polanya diputar/dirotasi.

\section{3). Cahaya}

Faktor cahaya yang dapat ditangkap oleh lensa kamera juga berperan penting karena apabila menampilakan marker ke kamera pada saat kondisi cahaya gelap/kurang terang, ataupun kondisi cahaya sangat terang/silau maka kamera akan susah dalam mengenali marker dan objek virtual tidak dapat tampil.

\section{KESIMPULAN}

Dari semua uraian dalam membuat Implementasi Augmented Reality Pemasaran Rumah Pada PT. Rika Bersaudara Sakti pada Brosur perumahan PT. Rika Bersaudara Sakti ini dapat diambil beberapa kesimpulan antara lain :

1. Pembuatan Implementasi Augmented Reality Pemasaran Rumah Pada PT. Rika Bersaudara Sakti pada Brosur perumahan PT. Rika Bersaudara Sakti ini menggunakan ARToolkit, SketchUp 8 Pro, Blender dan Adobe PhotoShop CS4.

2. Metode pengembangan yang digunakan yaitu metode pengebangan multimedia yang berawal dari concept, design, material, assembly, testing dan distribution.

3. Type perumahan yang dipasarkan oleh PT. Rika Bersaudara Sakti ada 3 Type yaitu type 36, type 45 dan type 70.

4. Implementasi Augmented Reality Pemasaran Rumah Pada PT. Rika Bersaudara Sakti pada Brosur perumahan PT. Rika Bersaudara Sakti ini dapat menjadi salah satu media untuk memudahkan bagian pemasaran dalam memasarkan atau menawarkan rumah terhadapa konsumen, menarik minat para konsumen. serta memudahkan para konsumen mengetahui bentuk rumah yang ditawarkan.

\section{SARAN}

Setelah melakukan penelitian di lapangan, maka dengan ini saran-saran yang akan dikemukakan adalah sebagai berikut :

1. Brosur ini dapat dikembangkan dan media untuk menampilkan dapat dikembangkan untuk ke platform lain contohnya smartphone android.

2. Menambahkan fitur 3D animasi yang lebih menarik agar tampilan tidak terlalu monoton, sehingga menjadi media promosi yang lebih interaktif.

3. Memberikan spesifikasi yang lebih detail dalam aplikasi sehingga mempermudah bagian pemasaran dalam mejelaskan kepada konsumen.

\section{DAFTAR PUSTAKA}

Alma, Buchari. 2007. Manajemen Pemasaran dan Pemasaran Jasa. Edisi Revisi. Bandung : Alfabeta.

Andriyadi, Anggi. 2012. Augmented Reality With ARToolkit. Jakarta: NulisBuku

Azuma, R.T. 2014. A Survey Of Augmented Reality. Presence : Teleoperators and Virtual Environments. Hughes Research Laboratories. Los Angeles

Billinghurst, Mark dkk. (2007). Emerging Technologies of Augmented Reality: Interfaces and Design. I dea Group Publishing. Idea Group Inc. United States of America.

Binanto, Iwan. 2010. Multimedia Digital - Dasar Teori dan Pengembangannya. Yogyakarta: Andi.

Budiman, Arif. 2009. Pengertian Brosur. http://army arif.blogspot.com/2009/12/pengertian-brosur.html. ( di akses Selasa, 7 Juni 2016 jam 11:15).

Chari, dkk. 2008. Augmented Reality Using Over Segmentation. Center for Visual Information Technology. International Institute of Information Technology. Telagana India.

Jogiyanto, Hartono. 2007. Analisis dan Desain Sistem Informasi, Edisi III. Yogyakarta: Andi. 